\title{
Rethinking the division of labor between tutorial writers and instructors with respect to fostering equitable team dynamics
}

\author{
Hannah C. Sabo* and Andrew Elby ${ }^{\dagger}$ \\ Department of Teaching \& Learning, Policy \& Leadership, University of Maryland, \\ College Park, Maryland 20742, USA
}

(Received 8 July 2019; accepted 28 April 2020; published 4 December 2020)

\begin{abstract}
[This paper is part of the Focused Collection on Curriculum Development: Theory into Design.] This paper proposes the rethinking of the division of labor between physics education research curriculum developers and classroom instructors. Historically, both curriculum developers and instructors have taken responsibility for fostering students' conceptual development, epistemological development, and other learning goals related to physics content knowledge and practices or process skills. By contrast, responsibility for fostering productive group dynamics has been taken up almost entirely by instructors. Tutorial and lab developers structure their materials to be used in small groups, but have not generally designed, tested, and refined their materials to minimize problematic group dynamics. In this paper, we argue that the written tutorial can and should do more to prevent negative group dynamics from arising. To make this claim plausible, we describe an example from our own experience. While revising a tutorial, we noticed some problematic dynamics emerging; one of the students was unfairly blamed for a simulationsetting mistake and was later left out of a conversation. We came up with hypotheses about factors that might have contributed to those dynamics. A few of those factors, we argue, could be addressed in part through tutorial revision. While acknowledging that instructors will always have more capacity and hence more responsibility than curriculum writers to foster productive group dynamics, we call for tutorial writers, during the testing and revision of their materials, to monitor how the tutorial impacts team dynamics and to be transparent (in publications and presentations) about how they modified the tutorial to address problematic dynamics they observed.
\end{abstract}

DOI: 10.1103/PhysRevPhysEducRes.16.020142

\section{INTRODUCTION}

This paper argues for rethinking one aspect of the instructional division of labor between curriculum developers and classroom instructors. Generally, the curriculum developer (tutorial author, lab author, or activity sheet writer) and the instructor (or facilitator) share responsibility for fostering students' conceptual and/or epistemological development. By contrast, in physics education research (PER), we generally assume that the instructor takes sole or primary responsibility for fostering good team dynamics, as represented in Fig. 1. We advocate for curriculum developers to attend to the kinds of conversations their activity sheets afford - not just at the coarse grain size of encouraging group discussion, but also at a finer grain size.

\footnotetext{
"hsabo@terpmail.umd.edu

elby@umd.edu
}

Published by the American Physical Society under the terms of the Creative Commons Attribution 4.0 International license. Further distribution of this work must maintain attribution to the author(s) and the published article's title, journal citation, and DOI.
To illustrate both the feasibility and value of attending to subtle effects of question sequencing and wording on student group dynamics, we analyze a segment of student discourse from their work through a draft of a PhET-based tutorial. Our tutorial, we argue, contributes to an inequitable teamwork dynamic, but can be revised in ways

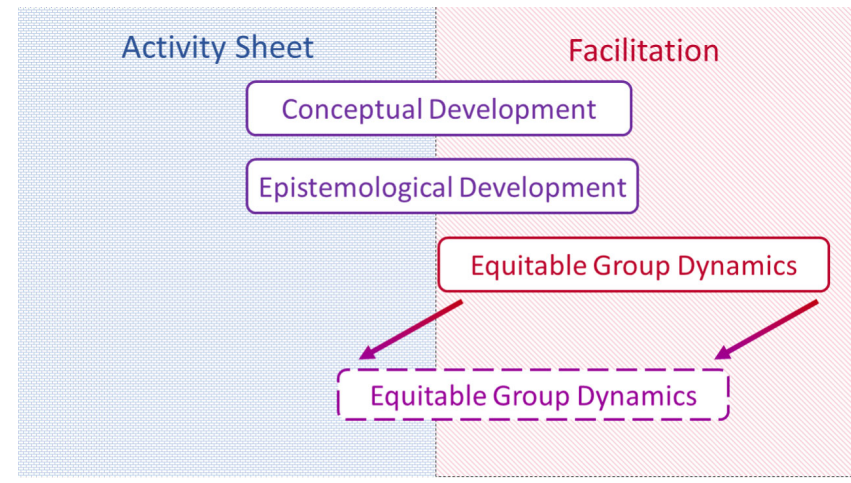

FIG. 1. Division of labor between activity sheet developers and classroom facilitators. We argue that developers should take on a greater share of responsibility for fostering equitable team dynamics. 
that could reduce the risk of these inequitable dynamics arising. To illustrate how we spotted what we thought were problematic dynamics, we present a transcript of the relevant segments of student conversation and describe what the first author noticed in real time as an observer. Then we check this quick, informal analysis against a second, in-depth interaction analysis. We then discuss how these analyses suggest possible revisions to the tutorial that could help address the problematic dynamic. In our example, the outcome of running the PhET simulation deviates so dramatically from the students' expectations that they think the person controlling the computer, Zoe, set up the simulation incorrectly. She gets blamed despite having set up the simulation correctly. Our ideas for tutorial revisions to mitigate this kind of dynamic might or might not work; like any potential tutorial revisions, they would need to be tested and refined in the usual iterative cycle by which tutorials are improved. Our point is simply that fostering equitable group dynamics, like fostering conceptual development, should be an outcome that curriculum developers pursue during the iterative refinement process.

Before diving into our example, however, we need to situate our argument in the literature by analyzing what data and learning outcomes other tutorial developers have foregrounded in their tutorial assessments. We assume the outcomes that were assessed also helped to drive the tutorial revision process, though of course other outcomes might have been monitored as well, formally or informally.

\section{LITERATURE REVIEW: WHAT OUTCOMES DRIVE TUTORIAL ASSESSMENT?}

This literature review serves two purposes. First, it provides an overview of the learning outcomes assessed by researchers and the methods used to assess them during the revision and testing phases, as reported in researchers' published work. This is meant to serve as a resource, particularly for new PER scholars getting into tutorial development and wishing to situate their work within that literature. Second, the literature review supports our argument that tutorial developers have not reported observing group dynamics and making revisions aimed at improving those dynamics (though we suspect tutorial developers do so informally).

For the purpose of this paper, we define "tutorial" broadly as a guided activity sheet aimed at teaching physics concepts and/or practices through a process of small-group inquiry. So, labs and invention tasks less guided than typical tutorials are still tutorials.

We primarily investigate the learning outcomes targeted during tutorial design, showing that most developers target conceptual understanding-typically from a misconceptions or student-difficulties perspective-and/or other cognitive constructs such as epistemological growth. We also explore the research and evaluation methods authors use to inform revisions. We argue that the most common research designs, namely, pre-post testing, treatment vs comparison groups, and interviews (other than think-aloud protocols), provide a limited window into students' learning processes while working through the tutorial, including the role of group dynamics. These methods thereby restrict the nature of the tutorial revisions that the research can inform. None of the papers we reviewed targeted productive group dynamics as a learning outcome or included observations of students' working through the tutorial as data.

Literature review methods.-Because of the specialized nature of physics education research, we selected journals and conference proceedings targeted at physics and science education research rather than searching a large database. We acknowledge that many other DBER communities also conduct research and development on activity sheets designed for collaborative active learning; however, the PER tutorial development community has not drawn extensively on this work. Rather than looking outward, we turn our focus inward, on tutorial development within the PER community.

In our search, we included the following journals: PRSTPER and PRPER, PERC Proceedings, American Journal of Physics, The Physics Teacher, Cognition \& Instruction, Journal of Research in Science Teaching, Physics Education, and the Journal of the Learning Sciences. To be included, the research had to address tutorial(s), question sequence(s), or question types aimed at undergraduate, introductory physics students. The exception to this was Ref. [1], which discusses a paired-question technique later deployed in introductory undergraduate physics tutorials [2]. We did not include papers on upper-division physics tutorials, though an informal scan through that literature suggested that the patterns documented below apply to the upper-division tutorial literature, too. Twenty-five articles, all reporting empirical studies, fit our selection criteria. For a full list of the literature included in this review, see Appendix A.

As we read each article, we focused on what constructs and associated learning outcomes the authors oriented to in the process of tutorial design, such as conceptual correctness or epistemological sophistication. We also focused on how the researchers assessed the tutorials' effectiveness. Because none of the papers reported on the messy details of the tutorial refinement process, we cannot know for sure whether other constructs and learning outcomes were also targeted during the refinement process. Still, we can reasonably infer that the reported targets of assessment were likely foregrounded during the refinement process. We return to this point below.

\section{A. Literature review findings}

Of the twenty-five articles we identified, twenty-two focused on refinement of at least one tutorial. One addressed a full course redesign [2], and two addressed specific types of questions $[1,3]$.

In terms of learning outcomes, twenty-two were focused on conceptual change, fourteen of which 
took a misconceptions - or student difficulties—oriented approach to tutorial design. Three papers focused on epistemology. Throughout this literature review, we highlight these patterns in the research methods and in the assessed constructs and outcomes. To show the range of studies, we also describe in more detail some of the studies that break from these patterns.

\section{Assessed constructs and learning outcomes: Conceptual change focused tutorials}

All but three articles assessed conceptual change, though several also explored other learning outcomes, as discussed below. Most of these studies used pre-post testing, sometimes in conjunction with other methods, to determine the students' conceptual growth [1,4-14]. To pre-post test, researchers administer a written assessment, typically one or more qualitative conceptual physics question, before and after students complete the tutorial to see how students' responses improve, and then revise the tutorial as needed. This cycle is often repeated for several iterations. Sometimes, as a last step, tutorial authors test the tutorial in contexts outside of the initial course. For example, after Wosilait et al. [15] first tested the tutorial in the calculusbased course, then they tested it in the UW algebra-based course and at other universities and two-year colleges.

In terms of the strategies employed by the tutorials to foster conceptual growth, most of the studies fell into one of three categories, discussed in the next three subsections.

(a) Eliciting, confronting, and resolving misconceptions.-From the early 1990s, three articles from the University of Washington detail the Physics Education Group's process of curriculum design [16-18]. Their tutorials are designed for discussion sections of large lecture courses, though they can and have been used in other settings. Many later studies followed the same process $[4,5,7-11,13,15$, $19,20]$. Before designing the tutorial, the researcherauthors either investigate common student difficulties around a topic or look up previously researched misconceptions. The authors then write a tutorial usually incorporating at least one "elicit, confront, resolve" sequence [16,17]. This sequence starts by asking students a specific, contextualized physics question that is likely to elicit a misconception or student difficulty. The next step involves helping students spot a conflict between their conception and a phenomenon or other conception. Finally, the tutorial tries to help students reach a satisfying resolution of the conflict.

(b) Scaffolding-Some researchers explored how the degree or type of guidance and scaffolding included in the tutorial impacted students' conceptual gains. For instance, Lindstrøm and Sharma created a series of activities which included a summary of the lecture, were given a concept map, and standard quantitative problems [21]. They compared these tutorials to the less guided approach of their traditional recitation section, which included the same word problems only. Several other tutorial designers focused on assessing the role of a particular analogy in helping students learn $[12,22,23]$. For example, Kuo and Weiman designed a tutorial to guide students in learning to read off the electric field from an electric potential map, using an analogy to reading off the slope of the ground from a topographical map [12].

When testing the efficacy of a given type of scaffolding, researchers often divide students into comparison groups, consisting groups receiving the scaffolded tutorial vs traditional instruction, or tutorial A vs tutorial B, or the old vs new version of the same tutorial (to evaluate refinements), or tutorial A vs another task. Researchers compare how the two groups perform, usually on a conceptual assessment. Many authors employed the comparison groups strategy, either in addition to or instead of pre-post testing [6,8-10,12,14,17-19,21-25].

(c) General rule vs contrasting cases.-Some studies used comparison groups to contrast the benefits of different cognitive processes. They also compared the scaffolding designed to support those processes $[6,12,14]$. Within a given study, one tutorial follows the predict-observe-explain model for various, individual cases, such as a wire loop getting pushed into a region of constant magnetic field and a stationary wire loop in a region of steadily increasing magnetic field. The other tutorial presents all the cases up front and asks students to generate a rule to explain all the phenomenon. The researchers hypothesized, and found, that students using the "generate a rule" tutorial would orient to the deep structure of the topic rather than the surface features of the cases, achieving greater conceptual understanding $[6,14]$.

\section{Other assessed constructs and learning outcomes}

We now turn to the smaller number of studies that focused primarily on constructs other than conceptual understanding, starting with tutorial-based studies of cognitive processes.

(a) Student cognition.-The general rule vs contrasting cases studies we just described could be viewed as examples of this, since their point was to test a hypothesis about the utility of a particular cognitive activity, "general rule" creation. However, those studies looked at students' pre-post test gains. Many studies instead used various types of interviews with students, to probe their depth of understanding or their type of reasoning. For instance, Gette, Kryjevskaia, Stetzer, and Heron considered student cognition, specifically dual processing theory, to inform their tutorial design [24]. The authors found that students' 
difficulties might emerge not from a gap in their conceptual understanding, but rather, from responding based solely on their quick, "commons sense" response. According to dual processing theory, when a reasoner is presented with a problem, they have a quick gut-level response and sometimes, a slower, scrutinizing process where they check and if necessary, correct their gut-level response [26]. If the thinker has no reason to question their gut-level reaction, they will not scrutinize it. Working from the assumption that some student difficulties stem from failure to engage in such scrutinizing, Gette et al. used thinkaloud interviews to collect students' reasoning while working through a tutorial. Coding the transcripts into gut-level responses vs slower scrutinizations (when possible), the authors identified tutorial sections that failed to elicit slower scrutiny of students' gut-level responses and revised the tutorial accordingly.

(b) Student preference.--In addition to investigating effects of heavily scaffolded versus unscaffolded tutorials (see above), Lindstrøm and Sharma asked students which type of tutorial-their reformed tutorial or traditional workshops - they preferred and what they liked and disliked about each option [21]. (They found that students preferred their more structured approach to traditional quantitative problems.) Additionally, they studied students' attendance patterns, finding that some students switched from traditional workshops to the more scaffolded workshop, but not vice versa.

(c) Epistemology-focused tutorials.-Three articles focused on creating curriculum to develop students' epistemology rather than (or in addition to) their conceptual understanding. Redish and Hammer describe a course redesign that included designing tutorials aimed at refining students' epistemology and assessed using the Maryland Physics Expectations Survey, probing students' beliefs about what counts as learning and understanding in their physics class [2]. Conceptual developmental was also assessed. Elby [1] and Hu and Rebello [3] did not describe the design of a specific tutorial, focusing instead on how aspects of the question design helped students gain a more sophisticated epistemology of physics. Hu and Rebello interviewed each small group of their student participants twice. In one interview, the student group worked through a physics problem [3]. In the other interview, students considered a similar problem scenario but in the context of evaluating a hypothetical student debate where the hypothetical students approach the problem differently. Analyzing the videotaped interviews, the authors compared students' framing of their problem solving-e.g., as "plug and chug" versus mapping physical meaning onto math-to the epistemological views expressed while evaluating the hypothetical debate. This analysis enabled the authors to look for variations in student epistemologies based on task structure, which informs instruction aimed at tapping into the more sophisticated aspects of students' epistemologies.

\section{Literature review conclusion}

In summary, most published work on introductory physics tutorial development focuses on conceptual development, using pre-post testing and/or comparison groups to evaluate the tutorial's efficacy and to inform revisions. Several researchers also incorporated interviews, but not as the main assessment technique. Two researchers used interviews to evaluate students' cognitive processes [24] or their framing of the tasks [3]. Both Gette et al. and Hu and Rebello's work were published in the last six years. Perhaps assessment methods are broadening to focus more on learning processes rather than just before-and-after snapshots.

Furthermore, over the last 20 years, researchers have expanded the range of learning outcomes assessed to include not just conceptual development but also epistemologies and other constructs. Yet, a hole in the literature remains. Although productive group dynamics are needed to ensure that all students have the opportunity to benefit from a tutorial, and although tutorial advocates may take for granted that doing tutorials can help students develop communication and teamwork skills, these "soft skills" and group dynamics are not assessed and addressed in the published research.

We are not saying that tutorial developers ignore group dynamics. Indeed, we know from personal experience and from discussions with other research teams that tutorial developers often observe students working on their tutorials (sometimes while serving as an instructor or TA), noticing the productive and unproductive group dynamics that arise. Maybe they revise the tutorial based in part on these observations. But if so, they do not report on these observations of group dynamics and the associated tutorial revisions in their published work.

We posit that tutorials can contribute to promoting equity or to (re)producing inequity in group dynamics, in the sense of disrupting vs contributing to marginalization of group members - marginalization that is particularly pernicious if it reproduces broader patterns of marginalization in physics and in society, since a mechanism by which marginalizing cultural narratives and power imbalances get stabilized is through their reproduction in numerous local interactions [27]. Therefore, we argue, tutorial writers should attend to how the tutorial interacts with team dynamics. In the following sections, we show how a tutorial contributes to an inequitable interactional dynamic. We first show a moment that raised a red flag, and then provide an in-depth analysis of the video of the interaction to show that inequity between group mates did occur. We then detail some tutorial revisions that could perhaps prevent similar 
inequities from arising again. In this way, we argue that it is feasible and potentially productive for tutorial writers to analyze group dynamics in order to inform the revision of tutorials.

\section{THEORETICAL AND METHODOLOGICAL ORIENTATION}

\section{A. Theoretical commitments central to our argument}

In this paper, we do not adopt a theoretical framework for understanding student cognition and learning. The assumptions about learning on which our argument relies are simply that collaborative learning is likely to produce deeper learning of disciplinary concepts, deeper engagement in disciplinary practices, and deeper identification with the discipline when the group dynamics allow all students to participate, produce a range of ideas that are respectfully discussed and debated, and help all participants feel like they belong in the group. These assumptions are consistent with all learning theories of which we are aware and are supported by a range of studies undertaken from various theoretical perspectives [28-30].

To the extent we have theoretical commitments, they are of the type discussed in curriculum theory and foundations of education courses, which address questions like what "counts" as curriculum and what is the purpose of schooling [31]. We think the so-called "soft" skills that students can develop through collaborative active learning, such as close listening, communication of ideas, respectful interactions, etc., are important learning objectives, just as important as the physics concepts and "hard" problem-solving skills that physics curricular materials typically target more explicitly. We also think that fostering such skills is in the purview of curriculum (including written tutorials) as well as in the purview of instruction. So, assuming tutorial revisions can improve group dynamics - an assumption we put forth without proof in hopes that we and other research groups will explore it in the future-then tutorial writers should consider how the structure or wording of a tutorial might contribute to patterns of problematic group dynamics revealed by clinical or classroom-based testing, and should try out revisions when possible.

\section{B. Methodological orientation of our illustrative example}

In this paper, we are arguing that it is feasible and productive for tutorial writers to

(i) observe the group dynamics of students working through a draft tutorial,

(ii) notice episodes or patterns of unproductive group dynamics,

(iii) generate informal hypotheses about how the tutorial itself might be contributing to those dynamics, and

(iv) generate potential revisions to the tutorial, some or all of which could be tested in later versions of the tutorial.
If video or detailed field notes of the observed group are collected, steps (ii) and (iii) can be done more carefully, as we will illustrate below. However, even if the tutorial writer's real-time observation of the tutorial group is all the "data" available, steps (ii) and (iii) are still possible—again, as we will illustrate below.

In "seeing" problematic group dynamics and in formulating possible fixes, the tutorial writer inevitably brings in their explicit and/or tacit theoretical and methodological orientation toward analyzing such dynamics. For this reason, we now describe the methodology with which the first author was approaching this data in her research. We do so not to advocate for this particular methodology, but simply to help readers understand our own orientations.

Interactional sociolinguistics is a branch of discourse analysis which investigates how meaning is generated by looking at interactions and the contexts in which they occur, especially by investigating the speech that occurs. Our analysis incorporates not only the interactions among students, but also the interactions between students and the PhET simulation, and between students and the printed tutorial.

Framing, one of the focuses of interactional sociolinguistics, investigates how situations are defined by participants-e.g., a student's view of "what is it that's going on here?"- and how those framings both shape and are shaped by the participants' interactions [32,33]. Within a given shared framing, distinct roles can emerge and can be taken on by students. Since these different roles have different rights and responsibilities, the roles students take on filter their interactions with each other and with the tutorial. The role of keyboard controller, the student who holds the keyboard and mouse and hence controls the simulation, will play a role (no pun intended) in our analysis below.

Below, we analyze two segments of interaction that the first author flagged in real time as problematic. We analyze each segment twice. The first, quick analysis rehashes what the first author noticed in real time, mirroring what a tutorial instructor observing the group can see. The second analysis uses video we collected (for research purposes) to take a deeper look at the interaction. In this paper the point of doing so is not to generate new insights that contribute to research, but rather, to confirm, disconfirm, and/or flesh out the quick analysis. Tutorial writers who happen to be collecting research data would be able to do this kind of "second look" (re)analysis. The transcripts for these second-look analyses use Waring's conversation analytic transcription conventions [34], available in Appendix C, to capture pauses, particularly loud or soft talk, rushed or halting pacing, and so on. In these transcripts and descriptions, we try to include enough information for the reader to draw their own conclusions about the interaction, not just the information relevant to the points that we make [35].

\section{Background information: Participants and context}

In this section, we provide relevant details about the students and context of the interactions discussed below. 
Three students from the University of Maryland's Introductory Physics for Life Sciences (IPLS) courses were invited to participate in research interviews through email; the students received a financial compensation for their time. Three students were invited to participate in this interview: Zoe, who presents as a Black woman; Jonathan, who presents as an East Asian man; and Devran who presents as a South Asian man. All of the names are pseudonyms. Because the data was collected for tutorialrevision purposes, we do not have more information about the participants available.

In this session, the students were each given a copy of a tutorial covering the concept of gravity on a planetary scale (see Appendix B). This tutorial's format and flow were like tutorials students had previously used in the class; however, they had not yet covered this topic. The students were asked to engage in the simulation while working on the tutorial as a group. The observer (the first author) watched the students and took field notes as they worked. If the participants had a question about the tutorial or needed clarification of concepts, the observer took on the role of a teaching assistant. After the students had worked on the activity for $40 \mathrm{~min}$, the observer engaged the participants in a conversation about their experience of the activity and the simulation. For example, "What was the simulation like?" and "What was it like working on the tutorial with another student?" and about any specific instances marked in the field notes. The interviews were video recorded; Camtasia software simultaneously recorded the students and the computer screen [36]. One additional camera captured the students and the observer.

\section{ILLUSTRATIVE EXAMPLE: TUTORIAL CONTRIBUTING TO PROBLEMATIC DYNAMICS}

Watching the student group in person, the first author had her instructor and curriculum developer hat on, and same goes for the second author upon first viewing the video footage; we were looking for parts of the tutorial that needed revision. During this initial scan, we noticed a red flag. Zoe, who was in control of the keyboard and computer, was blamed (incorrectly) for choosing the wrong settings in the simulation; and not long afterward, she seemed to be left out of the conceptual conversation around the tutorial prompts. In this section, we first describe how we noticed the red flag during an initial watch. Then, we discuss a deeper analysis which confirms the moment to be problematic. In the quick look presentation below, we rely on transcript rather than our memories of what the students said, so that readers can hear-or rather, read-what we heard.

\section{A. Initial observation \\ 1. Laying the blame}

Within the first few seconds of the tutorial starting, Jonathan asked Zoe, "Do you wanna use the computer cause you're closest?" Zoe agreed to use the computer. The students seemed to develop roles, including managing the computer, a role Zoe played throughout the session.

Later, the tutorial instructed students to use the "ellipses" setting in the My Solar System PhET simulation [37]. The question the students responded to follows:

Go to the ellipses preset. Change the initial velocities of each of the planets to zero.

1) Predict what will happen when you run the simulation. Explicitly compare bodies to each other. Explain your reasoning.

2) Run the simulation.

i) Describe what happened to each of the three small bodies.

ii) Is this what you expected? Why did it behave this way?

The purpose of this activity was to see how different radii impacted the motion (and therefore the gravitational force and resulting acceleration). The following moment occurred as Zoe, Devran, and Jonathan checked their prediction.

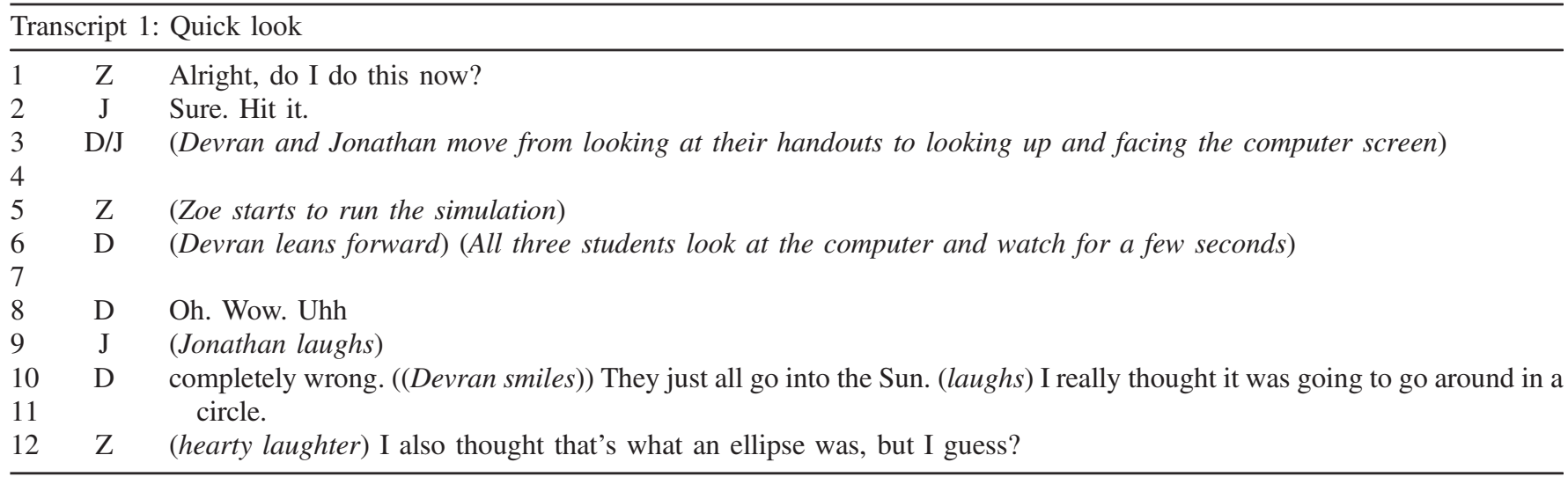

(Table continued) 
Table (Continued)

Transcript 1: Quick look

\begin{tabular}{|c|c|c|}
\hline $\begin{array}{l}13 \\
14\end{array}$ & $\mathrm{~J}$ & Wow. Wait, did we pick ellipse, Is that what that (points at computer screen) \\
\hline 15 & Z & Oh. When did that happen? I really- \\
\hline 16 & $\mathrm{~J}$ & we just killed three bodies. Three \\
\hline 17 & $\mathrm{Z}$ & Oh no (Zoe resets the simulation) \\
\hline 18 & $\mathrm{D}$ & $*_{\text {indistinguishable } *_{-}}$ \\
\hline 19 & $\mathrm{Z}$ & Ah. Why did I do that! \\
\hline 20 & $\mathrm{~J}$ & It's all good \\
\hline 21 & $\mathrm{Z}$ & Well \\
\hline $\begin{array}{l}22 \\
23 \\
24\end{array}$ & $\mathrm{D}$ & $\begin{array}{l}\text { Just change the velocity to zero. (Devran sits up from the table, then leans back into his chair) } \\
\text { (Jonathan sits up and leans back at the same time as Devran) }\end{array}$ \\
\hline 25 & $\mathrm{Z}$ & \\
\hline 26 & $\mathrm{~J}$ & $\begin{array}{l}\text { Clearly I've had a long day (resetting the simulation) } \\
\text { (Jonathan laughs, nods, and sits forward) (a few second pause) }\end{array}$ \\
\hline 27 & & (Jonatnan laughs, hoas, ana sils jorwara) (a Iew second pause) \\
\hline 28 & $\mathrm{D}$ & Actually, no wait, that's what it was before. \\
\hline 29 & $\mathrm{~J}$ & Hm. Change the-that's when we changed it to zero. (still using the computer to reset the simulation) \\
\hline $\begin{array}{l}30 \\
31\end{array}$ & $\mathrm{Z}$ & \\
\hline 32 & $\mathrm{D}$ & Yea, we changed it to zero, that's what's gonna happen. \\
\hline $\begin{array}{l}33 \\
34\end{array}$ & $\mathrm{Z}$ & $\begin{array}{l}\text { (Zoe resets the simulation) This is what should happen (runs the simulation) (The computer shows the three bodies } \\
\text { orbiting the Sun) }\end{array}$ \\
\hline $\begin{array}{l}35 \\
36\end{array}$ & $\mathrm{D}$ & $\begin{array}{l}\text { No, but see. That makes sense because there was initial velocity before. There was, Um, it's already moving in a direction, } \\
\text { so the force is going to influence it, }\end{array}$ \\
\hline 37 & & but it's not going to go straight into the Sun. But if you put all velocities to zero \\
\hline 38 & & then the \\
\hline 39 & Z & Oh. \\
\hline $\begin{array}{l}40 \\
41\end{array}$ & $\mathrm{D}$ & gravitational force on those masses- (Devran moves from facing straight forward to turning and facing Jonathan) \\
\hline 42 & $\mathrm{~J}$ & (Jonathan and Zoe look at Devran while he is talking) \\
\hline 43 & $\mathrm{D}$ & Yea it's just going to collide (moves his left fist into his right palm \\
\hline 44 & $\mathrm{Z}$ & (overlapping with Jonathan) yea. it's just going to go straight to it \\
\hline 45 & $\mathrm{~J}$ & $\mathrm{Oh}$, so, it was correct $=$ \\
\hline 46 & $\mathrm{Z}$ & Uhm. (Devran's gaze moves to Zoe, he does not turn his head) \\
\hline 47 & $\mathrm{D}$ & because it changed back \\
\hline 48 & & (Jonathan looks at Zoe) No, you were right. We did it right the first time. \\
\hline
\end{tabular}

Jonathan, Devran, and Zoe predicted that the planets would orbit the Sun. Instead, the planets fell straight into the Sun. As tutorial writers, we had not intended this to be a surprise. We had wanted students to focus on how the planets' distance from the Sun, for equally massive planets, affected the gravitational force exerted on them and the resulting motion. Instead of discussing this issue, the students realized that the initial velocity of the planets is what allows for them to orbit. So, this interaction leads to conceptual progress, though not about the topic we had intended.

However, during this interaction, the students blamed Zoe for the simulation going wrong. Jonathan, Devran, and Zoe all thought that the wrong settings had been chosen. Zoe apologizes to Devran and Jonathan. Jonathan accepts her apology, and Devran asks for her to just run the simulation again, with the correct settings. Eventually, they figure out that Zoe did not make an error, and they were able to have a productive conceptual discussion. However, we were concerned that the tutorial was unintentionally confusing and that the students blamed Zoe for that confusion. And we saw evidence that the use of the "ellipses" preset may have contributed to this dynamic, given Zoe's and Jonathan's mention of ellipses and the ellipses preset in line 12-13.

\section{Zoe is left out of the discussion}

Five minutes later, Zoe is setting up the computer to run a trial. The students were asked to predict how doubling the mass of planets (as compared to the previous setup) would impact the time they took to fall into the Sun. While she is working on the simulation, Devran and Jonathan have a conceptual discussion about their prediction, based on the universal law of gravitation. 


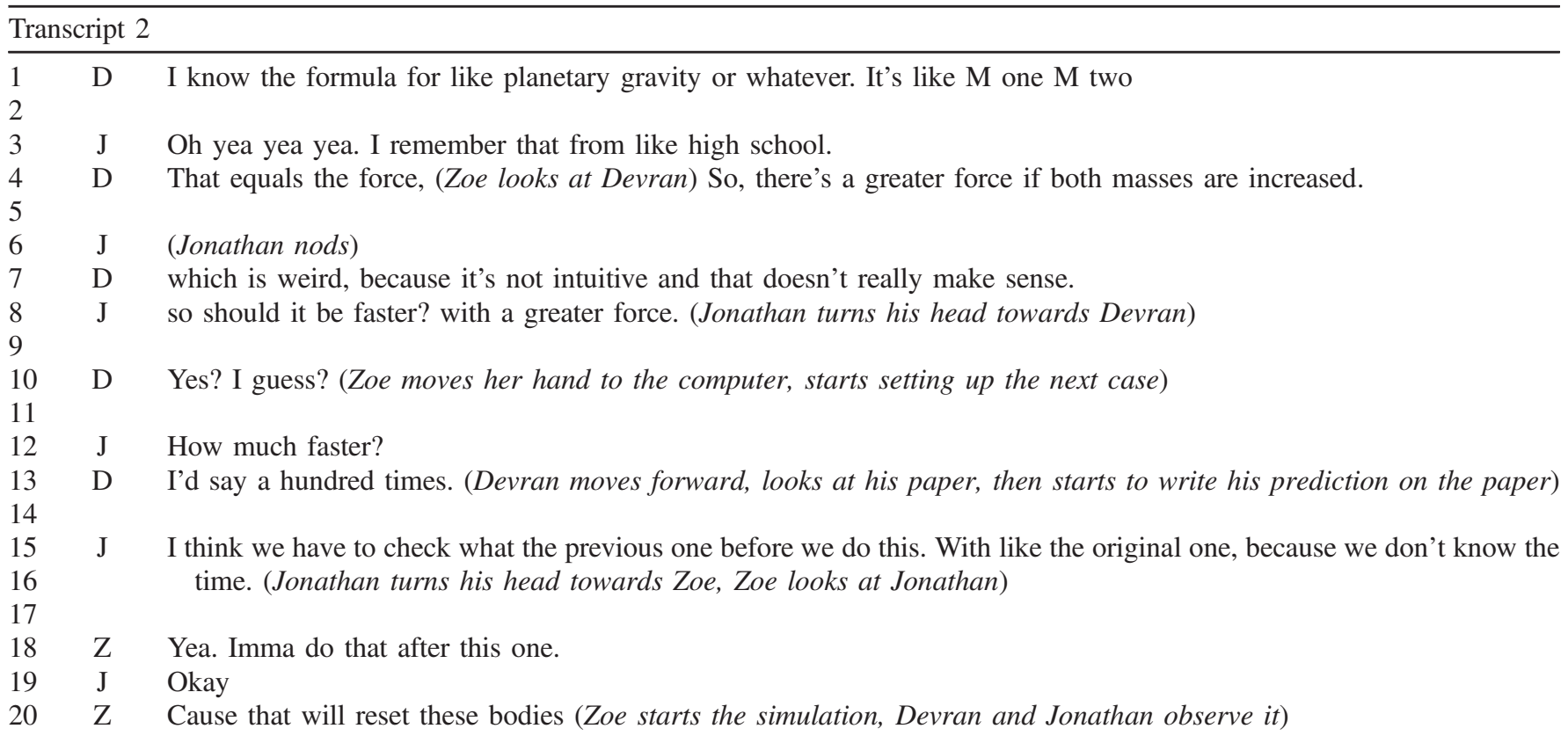

In line 1, Devran recalls a formula from his previous experiences. In line 8, Jonathan draws an inference from Devran's recollection of the formula. He says, "So it would be faster? with greater force?" In line 12, he further refines Devran and his prediction by asking "How much faster?"

As observers, we noticed Jonathan and Devran try to make a prediction based on Devran's recollection of a formula from high school. In doing so, they engage in a conceptual conversation. However, Zoe appeared to be left out of the conversation and was instead adjusting the simulation; Devran and Jonathan called on her (line 16-17) only when they were ready to observe the simulation. So, she missed the chance to predict and engage with the universal law of gravitation. As observers, it looked like Zoe had been relegated to the role of computer controller, with no space for her to contribute to the conversations around the tutorials' questions. In making this point, we do not want to devalue the intellectual work she was doing. Throughout the tutorial, she translates the conceptual conversations and predictions into actions in the simulation. However, in the physics classroom, this work is less valued and frequently not translated into grades; she was much more likely to be tested, via paper-based problems, on the universal law of gravitation.

In summary, upon first watching those segments, we noticed Zoe getting temporarily blamed for a (nonexistent) mistake in the simulation settings she controlled, followed by stretches of conversation in which she did not verbally take part while she was adjusting the simulation (including the particular segment shown above). Because we had video of these interactions, however, we were able to take a closer second look, to confirm, disconfirm, or refine our initial impressions.

\section{B. In-depth analysis of data segments \\ 1. The blame game}

The following subsection includes an in-depth interaction analysis of the first transcript, now displayed with Waring's Conversation Analysis Transcript Convention [34]. These conventions are in Appendix C, which we recommend having next to the transcript while reading this.

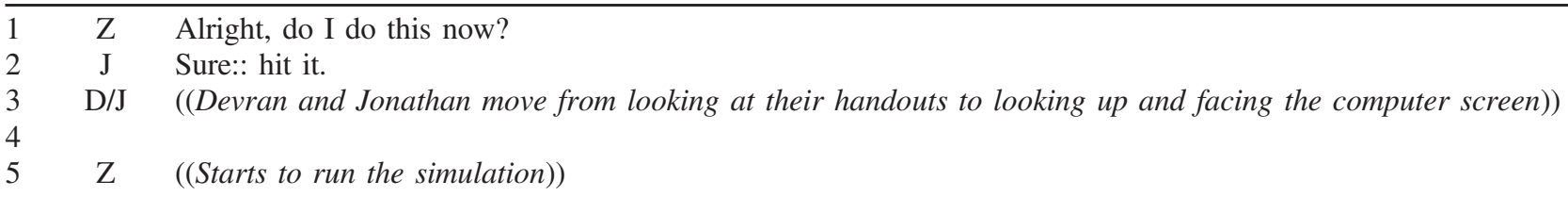




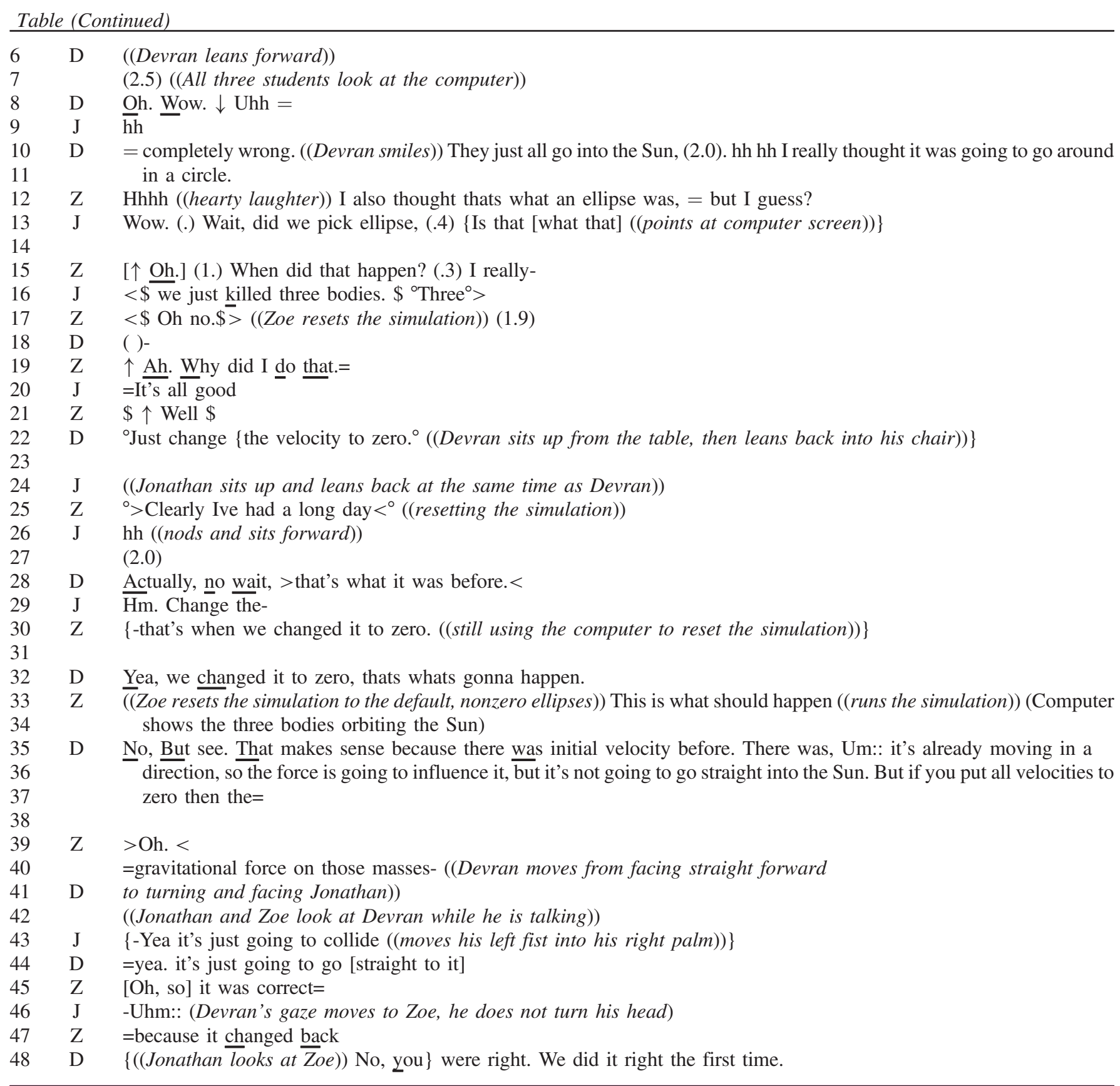

Because Zoe controls the computer, it is she who asks if Jonathan and Devran if they are ready for her to start the simulation (line 1). Jonathan responds "Sure, hit it," indicating that he is paying attention and giving her the go ahead.

Instead of seeing the planets orbit the Sun, as the students expected, the planets fall towards the Sun. All students were leaning forward and paying attention to the computer. For the first $2.5 \mathrm{sec}$, the students silently observe what happens. Then, Devran starts audibly responding: "Oh, wow. Uhh" (line 8). He emphasizes the start of these words, suggesting genuine surprise. His pitch drops, which often indicates the speaker beginning to think something through. In lines 10-11, Devran narrates the outcome they had just seen. He then inhales and laughs. He continues to say he thought the planets would go in a circle (line 11), echoing their prediction. Jonathan's reaction also indicates surprise: $\mathrm{He}$ reacts by audibly inhaling, and almost laughing.

Zoe responds to Devran by heartily laughing and expressing shock about the outcome (line 12). Responding to Devran's expectation, she states she thought an ellipse was something that went around in a circle (line 12), and she second guesses her own knowledge base. 
In line 13, after hearing "ellipses," Jonathan considered that the group may have made a mistake. He asks Zoe "wait, did we pick ellipse [as the preset]." At this moment, the "preset" box in the simulation no longer displays "ellipses." We infer that, since the outcome of running the simulation diverged far from what they expected and since the preset does not appear to be "ellipses," he thought there may have been a user error. Jonathan uses "we" when asking, nominally attributing the possible error to the group.

In line 19, however, Zoe says "Ah. Why did I do that?" She is using "I," as she was controlling the computer. In doing so, and in questioning what she did, she takes "credit" (really, blame) for not picking the right preset. Jonathan responds "it's all good," in line 20. He has latched on to what Zoe was saying, immediately saying that it was alright. Whatever the good intentions, the statement also acknowledges that it was Zoe's fault. In this way, Zoe, Jonathan, and Devran treat Zoe as having made an error setting up the simulation.

She then resets the simulation to rerun it. In line 22, Devran quietly says, "just change the velocities to zero," as he reclines away from the table. Prior to the perceived mistake, Jonathan and Devran did not micromanage Zoe's control of the computer.

As Zoe resets the simulation to the instructed setup, Devran realizes that the "new" setup matched what it had been before. In line 28, he quickly tells his groupmates, "that's what it was before." In line 30, Zoe uses the pronoun we to describe a change that she made to the computer. She groups herself with Devran and Jonathan, framing her actions as a group endeavor. In line 32, Devran echoes the use of the word "we," reiterating the collective identity of the group. Then, Zoe chooses the ellipses preset without changing the planet velocities to zero. The planets do indeed orbit the Sun, which she states is "what should happen." In line 35, Devran explains that the tutorial's requested setup, with planet velocities set to zero, would lead to planets falling into the Sun instead of orbiting, which occurs when the planets have initial velocities. After confirming that the planets should indeed collide with the Sun when they have zero initial velocities, Zoe says "Oh, so it was correct" referring to the first setup of the simulation-the setup the group thought was erroneous. She does not explicitly give herself credit for being correct all along; she simply states that the first setup was right, and that no error was made. In line 48, Devran affirms that she was correct, saying "No you were right, we did it right the first time." Here, Devran tells her that she, as the person in control of the computer, was right. He also reaffirms the group's identity - that they had set up the computer correctly the first time.

In summary, although Devran and Jonathan end up acknowledging that Zoe did nothing wrong, for about a minute she was blamed for the perceived error. In that minute, Devran micromanages Zoe and she feels responsible for the alleged mistake. This, plausibly, reduced her credibility and agency in the group. These three students were able to figure out what went wrong and explicitly remove blame from Zoe, perhaps due in part to Zoe's running the simulation with nonzero planet velocitieswhich helped Devran focus on and make sense of the difference between the planets having nonzero vs zero initial speeds. Still, we consider it problematic that she was blamed, for a few reasons. First, the unconscious emotional aftereffects of the blaming could linger into later interactions. Second, even if emotional aftereffects did not linger in this group, we can easily imagine another group of students getting misled by the name of the ellipses preset, blaming the computer operator for messing up when they observe the planets not traveling in ellipses, and then failing to figure out their mistake or failing to explicitly "unblame" the computer operator. And as discussed below, we see the tutorial as contributing to this "blame" dynamic.

\section{Zoe is left out: The importance of body language}

Even though Jonathan and Devran absolved Zoe of blame, she is still left out of their later conversations. A deeper interaction analysis is not needed to confirm that she does not speak until line 18 of transcript 2 above (Sec. IVA 2). So, instead of presenting a full interaction analysis, we supplement that verbal transcript with a closer look at the students' physical placements and body language when Jonathan and Devran were having the conceptual conversation about the gravitational force.

When Devran recalled the gravitational force formula from high school (transcript 2, line 1), he leaned backwards, away from the table. Jonathan mirrored Devran's movement and also leaned back. Immediately afterwards, Zoe starts setting up the simulation for the next run. Because of the computer placement, she remained leaning forward. Figure 2 shows the positioning of the students.

Devran and Jonathan have both leaned backwards away from the table and their worksheets as they discuss what will happen. Zoe is unable to mirror their body language; she is leaning forward and appears occupied with setting up the simulation. Furthermore, Devran has his right arm crossed over his body, while his left arm is open. Zoe is on his right side and is, therefore physically blocked from the conversation-not literally, but in terms of the subtle messaging sent by body language. Her body language mirrors this block; her head is in her left hand, and she is focused on the computer. Zoe's forward lean cuts her off from the conceptual conversation. On Devran's other side, his left arm is back and is open towards Jonathan. As they talk, they make eye contact (not shown in Fig. 2) and do not look at Zoe until asking her about the simulation.

In summary, the body positioning and body language during this interaction leave Zoe blocked out, mirroring the verbal conversation. From the interaction, it is unclear what combination of physical positioning, body language (likely unconscious), and Zoe's attention to the simulation makes 


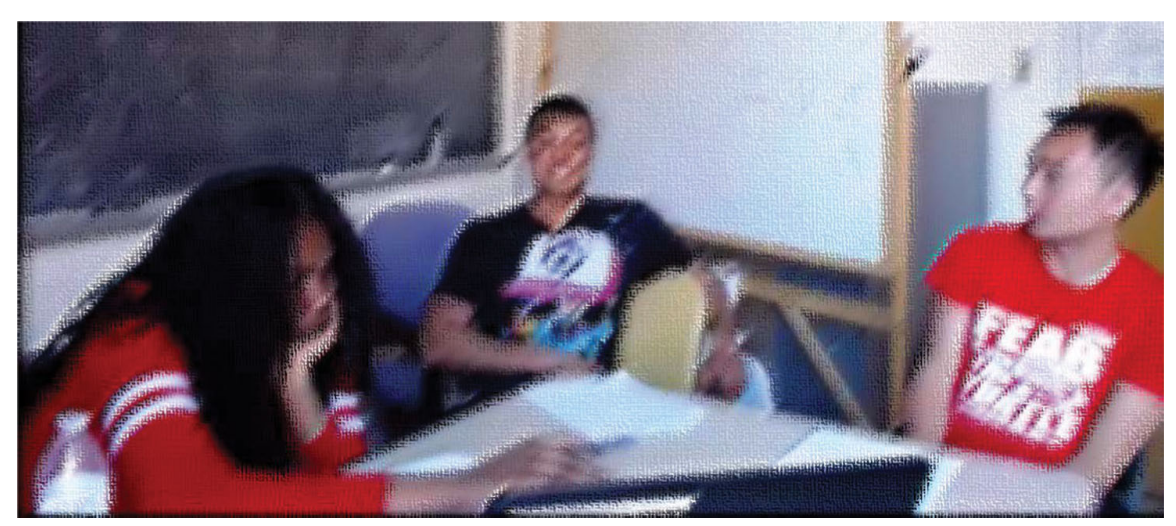

FIG. 2. Zoe is on the left, leaning towards the bottom center of the figure, where the computer is. Devran is in the middle, casually leaning back in his chair. Jonathan, on the right, has also leaned back, as he and Devran predict how the next run of the simulation will compare to the previous run.

it difficult for her to participate in the discussion. At the very least, however, it is likely that the physical positioning makes it harder for Zoe to enter the conversation than would be the case if the students were all facing each other with "open" body language.

\section{Analytical takeaways}

An inequitable dynamic arose between the students in the group. Specifically, Zoe, who presents as a Black woman, was asked to be in control of the computer by Jonathan, who presents an East Asian male. Zoe is blamed for a mistake she did not make, and then later, left out of the conceptual discussion.

We see a variety of factors, both systemic and local, which may have impacted the dynamic. As someone who presents as a Black woman, Zoe may carry multiple identities marginalized in physics and in American society more broadly. Presenting as Asian males, her group mates are marginalized in many American contexts, but less so in university physics. Since the clinical interview environment was clearly connected to physics and was not explicitly designed to disrupt these broader patterns of marginalization, the danger exists that the marginalization of African American women in physics could get (re)produced in this context [38].

At a more local-interactional level, early in the interaction, Zoe takes the blame for something which was not her fault. Even if an emotional memory from this episode does not unconsciously affect later interactions, Zoe's role as computer operator may have been in tension with her taking on a greater role as codiscusser of the tutorial questions, for a combination of three reasons: The interaction may have constructed "computer operator" and "question discusser" as two disjoint roles; and/or, the spatial positioning and body language of the other students may have "blocked" Zoe from the conversation; and/or, Zoe's attention to the simulation may have made full attention to the conversation impossible.
Ironically, in previous research, computer controller emerged as a prestigious role with more power $[39,40]$. This was not the case for Zoe. While in control of the computer, Zoe did valuable, but unseen work. This is the concrete, local-interactional sense in which we conceptualize the group dynamics as problematic and inequitable.

Based on our limited data, we cannot adequately address whether and how broader cultural narratives and power imbalances concerning women of color, and women of color in physics, affected these local interactions. Independent of the precise answer to this question, however, we consider it urgent to revise the tutorial to lessen the odds that such local-interactional inequities arise, because more equitable dynamics is an end in itself, because more equitable dynamics tend to lead to better problem solving $[41,42]$ and because some local-interactional inequities (re) produce broader systemic inequities in science, technology, engineering, and math (STEM) [40,43].

\section{POSSIBLE CHANGES TO THE TUTORIAL}

In the previous section, we showed how the tutorial may have contributed to an emerging problematic group dynamic. Here, we outline some potential changes to the tutorial inspired by our analyses. These changes have not yet been implemented: like any potential tutorial revisions, they would need to be tested. Our point in this section is to illustrate how observations of group dynamics can inform potential revisions, motivating a research agenda to start testing when and how such revisions "work."

\section{A. Changes to the use of the "ellipses" preset}

One section of the tutorial told students to use the ellipses preset. We chose this preset because it assigns the planets equal but negligible mass compared to the Sun, but different distances from the Sun-exactly the desired scenario. Instead of prompting this preset, the tutorial could instruct students to set up a similar system by hand. This would take more time, but students would not be as 
primed to expect the planets to orbit the Sun, and they would be reminded of the physical parameters. A downside to this approach, though, is that the computer operator's attention would be occupied for even more time, potentially causing them to miss out on the conceptual discussion. Furthermore, if the students had not expected the planets to orbit, they may not have figured out that nonzero initial velocity is what allows a planet to orbit instead of just falling into the Sun.

Another potential fix would be to keep the ellipses preset but to just state in the tutorial that the planets will no longer orbit when their initial velocities are changed to zero. This would likely prevent or lessen the students' expectation of (elliptical) orbits. But it would constrain the students' predictions-helping focus students on how distance from the Sun affects the gravitational force but failing to elicit what student might really think about this scenario.

The final potential change we brainstormed to mitigate the ellipses preset problem is to add a new tutorial section before the "problematic" one. In the new section, students would explore the effects of different initial velocities on the resulting orbits. Then, a question would ask the students to predict and test what happens when a planet's velocity is removed (set to zero). This section would likely lay the groundwork for later sections which focus on circular and elliptical orbits, and it could prevent students from expectation an elliptical orbit, even in the ellipses preset, when the planet's initial velocity is zero. However, adding a section would take up limited class time.

\section{B. Changes to impact the interactional dynamic}

In addition to addressing the ellipses preset problem, we brainstormed ways to directly disrupt the dynamic by which Zoe, the computer controller, got left out of the conceptual discussions.

One approach is to include explicit instructions in the tutorial to switch computer operators every section or two. To the extent that controlling the computer distracts the user from the conceptual conversation, rotating who controls the computer would share that burden among all students.

Another potential modification would involve engaging the whole group, not just the computer operator, in figuring out the needed simulation settings. So, in some question sequences, instead of the tutorial giving a detailed description of what the simulation setup should look like, the tutorial would ask something like "How can the simulation be set up to test the prediction you just made? Work together and come to consensus." A question like this would perhaps have made the tutorial setup an explicit conversation topic and could have pushed Jonathan and Devran to help Zoe instead of jumping ahead to the conceptual discussion without her.

Although this paper is about how tutorials could help prevent negative dynamics from arising, many factors are out of the tutorial's control. For example, Zoe was leaning forward, setting up the computer, while Devran and Jonathan were reclined away from the table, discussing the universal law of gravitation. She was not embodying the same physical space as they were. As tutorial developers, we can't address this directly, but we can add advice to the instructor's guide warning instructors to watch out for this body-positioning dynamic. The instructor's guide could include a more general suggestion to look out a student being left out of the conceptual discussion, with tips for preventing and mitigating this situation. So, we can use the instructor guide as a platform to communicate about the computer control issue and give tips on how to mitigate the negative dynamic. We can also ask instructors to make wireless keyboards and mice available, when possible.

To more directly take on the issue of marginalization and power imbalance in physics, the instructor's guide could suggest that instructors keep these systemic issues in mind when monitoring and intervening in group dynamics. All of our instructor's guides could suggest resources that researchers and activists have created to help facilitators create "safer" spaces for students historically marginalized in physics and STEM (e.g., resources and ideas from the Access Network [44]).

\section{DISCUSSION}

As shown above, a tutorial can contribute to negative team dynamics. We argued that tutorial authors can and should do what they can to minimize the tutorial's contribution to problematic team dynamics. This calls for careful observations of student groups working through the tutorial. In the process of making this argument, we also illustrated a small slice of the often-unseen process of tutorial revision. Specifically, we shared how we interpreted evidence of flaws in the tutorial and our brainstormed ideas, based largely on instructional intuitions, for potentially addressing those problems.

Pre-post testing, the most common form of tutorial assessment, will not reveal how teams of students work together on the tutorial. Our illustrative example details our process for coming up with potential refinements to our tutorial, to address group dynamics. Although the deeper analyses confirmed our initial impressions of how the group dynamics were going astray and added more nuance, our first-pass observations turned out to be sufficient to spot the ellipses preset problem and the Zoe-left-out problem. These kinds of first-pass observations do not require videotaping or even detailed field noting.

Indeed, we believe that tutorial authors notice these kinds of problematic group dynamics as they observe the tutorial in real time. Furthermore, we believe that sometimes, they make tutorial revisions based on these observations. However, these observations and associated changes are not included in research articles about the tutorials. Tutorial 
authors rely on their instructional intuitions, but this process is hidden from view in journal articles. We are advocating for more transparency around these sorts of changes to tutorials. Such transparency can be generative for other curriculum developers when they are building on each other's ideas for question types, sequencing decisions, and so on; instead of relying solely on the finished product (i.e., the revised tutorial itself), those other curriculum developers could also rely on the observations and instructional intuitions underlying the finished product. Such transparency could also be helpful to instructors implementing the tutorial. By understanding why questions are worded and sequenced in certain ways, the instructor can facilitate student discussions in ways that cohere with the tutorial's design, and can make more informed decisions about when and how to change the tutorial [45]. For example, if tutorial authors describe how observations impacted the flow of the tutorial, an instructor could understand how previous and upcoming sections of a tutorial depend on one another. Finally, such transparency could help other researchers. Reading about how (even informal) observations led to tutorial revisions, researchers could get ideas for research studies about how particular types of wording and sequencing correlate with students' interaction dynamics and learning.

In summary, we are advocating that curriculum developers attend to more than just conceptual growth; curriculum developers should be aware of the kinds of conversations that their tutorials afford and the learning benefits that it brings beyond cognitive gains. Transparency around these sorts of tutorial revisions would benefit instructors. While we do not think that a detailed description of every change the authors made to the tutorial would be helpful for instructors who wish to implement the curriculum, we believe that some insight into design decisions could benefit instructors, other curriculum developers, and researchers.

\section{CONCLUSION}

In this paper, we call for tutorial authors to attend to the tutorial's impact on interactional dynamics among students and to be more transparent as they report on the changes they make to the tutorial. The tutorial is one element of a system that sometimes produces inequitable group dynamics. The tutorial can be tested and revised to minimize its contribution to these inequities. In this paper, we show how observing the tutorial led to the identification of inequitable team dynamics and ultimately potential modifications to the tutorial. Tutorial authors regularly observe and tweak their tutorials on the basis of such observations. However, tutorial authors do not typically report these changes in research papers. And even in (rare?) cases when problematic team dynamics do not hinder conceptual growth, equitable dynamics are still important to the health of a physics classroom. Better interactions are important for their own sake. We want the physics classroom to be a humane place. Therefore, tutorials should promote more humane experiences.

\section{ACKNOWLEDGMENTS}

We thank Dr. Joe Redish, who let us recruit from his course; Zoe, Devran, and Jonathan for their participation in the research project, additionally including other participants. And we thank the University of Maryland Physics Education Research Group for their feedback throughout the process, especially Dr. Chandra Turpen and Dr. Ayush Gupta. We also thank our three anonymous referees and to guest editors for their careful feedback. Funding provided by NSF Grant No. 1245400 .

\section{APPENDIX A: LITERATURE TABLE}

This appendix contains the tutorial (written worksheet) that the students discussed in this article were using.

\begin{tabular}{|c|c|c|c|}
\hline Reference & Focusing on What? $\downarrow$ & Methods & Focus of tutorial \\
\hline [16] & $\begin{array}{c}\text { Misconceptions oriented, conceptual } \\
\text { change }\end{array}$ & $\begin{array}{c}\text { Interviews to find common } \\
\text { misconceptions }\end{array}$ & Electric circuits \\
\hline [17] & $\begin{array}{c}\text { Misconceptions oriented, conceptual } \\
\text { change }\end{array}$ & Comparison groups, pre-post tests & Electric circuits \\
\hline [18] & $\begin{array}{c}\text { Misconceptions oriented, conceptual } \\
\text { change }\end{array}$ & Comparison groups & Tension-Atwood's machine \\
\hline [20] & $\begin{array}{c}\text { Misconceptions oriented, conceptual } \\
\text { change }\end{array}$ & $\begin{array}{l}\text { Pre-post testing, interviews for } \\
\text { misconceptions }\end{array}$ & Light and shadow \\
\hline [4] & $\begin{array}{c}\text { Misconceptions oriented, conceptual } \\
\text { change }\end{array}$ & $\begin{array}{l}\text { Pre-post testing, interviews for } \\
\text { misconceptions }\end{array}$ & Electromagnetic waves \\
\hline [15] & $\begin{array}{c}\text { Misconceptions oriented, conceptual } \\
\text { change }\end{array}$ & $\begin{array}{l}\text { Pre-post testing, interviews for } \\
\text { misconceptions }\end{array}$ & Geometric optics and diffraction of light \\
\hline
\end{tabular}

(Table continued) 


\begin{tabular}{|c|c|c|c|}
\hline Reference & Focusing on What? $\downarrow$ & Methods & Focus of tutorial \\
\hline [9] & $\begin{array}{c}\text { Misconceptions oriented, conceptual } \\
\text { change }\end{array}$ & Pre-post testing, comparison groups & Buoyancy and Archimedes' principle \\
\hline [11] & $\begin{array}{c}\text { Misconceptions oriented, conceptual } \\
\text { change }\end{array}$ & $\begin{array}{l}\text { Pre-post testing, interviews for } \\
\text { misconceptions }\end{array}$ & Ideal gas law \\
\hline [8] & $\begin{array}{c}\text { Misconceptions oriented, conceptual } \\
\text { change }\end{array}$ & $\begin{array}{l}\text { Large scale identification of } \\
\text { misconceptions, pre-post testing, } \\
\text { comparison groups }\end{array}$ & Heat engines \\
\hline$[10]$ & $\begin{array}{c}\text { Misconceptions oriented, conceptual } \\
\text { change }\end{array}$ & $\begin{array}{l}\text { Pre-post testing, comparison groups, } \\
\text { interviews for misconceptions }\end{array}$ & Coulomb's law, Gauss's law \\
\hline [13] & $\begin{array}{c}\text { Misconceptions oriented, conceptual } \\
\text { change }\end{array}$ & $\begin{array}{l}\text { Large scale identification of } \\
\text { misconceptions, pre-post testing }\end{array}$ & Work and extended systems \\
\hline [19] & $\begin{array}{c}\text { Misconceptions oriented, conceptual } \\
\text { change }\end{array}$ & Comparison Groups & Electrical capacitance \\
\hline [7] & $\begin{array}{c}\text { Misconceptions oriented, conceptual } \\
\text { change }\end{array}$ & $\begin{array}{l}\text { Pre-post testing, interviews for depth / } \\
\text { process of learning }\end{array}$ & Dynamics of rigid bodies \\
\hline [5] & $\begin{array}{c}\text { Misconceptions oriented, conceptual } \\
\text { change }\end{array}$ & $\begin{array}{l}\text { Large scale identification of } \\
\text { misconceptions, pre-post testing }\end{array}$ & Rolling motion \\
\hline [21] & $\begin{array}{c}\text { Level of scaffolding and student } \\
\text { preference** }\end{array}$ & $\begin{array}{c}\text { Comparison Groups, observations, } \\
\text { focus group }\end{array}$ & Forces and energy \\
\hline [22] & Analogical scaffolding & $\begin{array}{l}\text { interviews for misconceptions, } \\
\text { comparison groups }\end{array}$ & Probability in quantum mechanics \\
\hline$[25]$ & Analogical scaffolding & $\begin{array}{c}\text { Pre-post testing interviews, comparison } \\
\text { groups }\end{array}$ & Electromagnetic waves \\
\hline$[12]$ & $\begin{array}{l}\text { General Rule vs Contrasting, } \\
\text { analogical scaffolding }\end{array}$ & Pre-post testing, comparison groups & Electric field and electric field potential \\
\hline [23] & Analogical scaffolding & Comparison groups, interviews & Forces \\
\hline [14] & General rule vs contrasting cases & Pre-post testing, comparison groups & Electric flux \\
\hline [6] & General rule vs contrasting cases & Pre-post testing, comparison groups & Electric flux \\
\hline [24] & Dual-process theory and cognition & Comparison groups, interviews & Buoyancy \\
\hline [1] & Epistemology & Pre-post testing & $\begin{array}{c}\text { Question type: epistemological focused } \\
\text { curriculum }\end{array}$ \\
\hline [3] & Epistemology & Group interviews & $\begin{array}{c}\text { Question type: Hypothetical debate } \\
\text { problems }\end{array}$ \\
\hline [2] & Epistemology & Tutorial observations, pre-post testing & $\begin{array}{c}\text { Course reform, including development } \\
\text { of tutorials }\end{array}$ \\
\hline
\end{tabular}

\section{APPENDIX B: COPY OF THE TUTORIAL}

An Introduction to Orbits

\section{Orienting with the simulation}

Go to http://phet.colorado.edu/en/simulation/legacy/mysolar-system (or Google PhET My Solar System) and open the "My Solar System" simulation.

Spend 5 minutes playing with the simulation and exploring its features.

A. What is one unexpected thing that you found while playing with the simulation? Why was it unexpected?

B. What does "system-centered" mean?

Notice that if you use your mouse to hover over a body, you get its position and velocity components.

\section{Gravitational force}

There's a slider on the bottom right. Turn the slider so that it is $1 / 4$ of the way between accurate and fast (closer to accurate). Also, make sure that System-Centered is turned on.

\section{A. The gravitational field}

Go to the ellipses preset. Change the initial velocities of each of the planets to zero.

A. Record the distances between the Sun (body 1) and each of the planets (bodies 2, 3, and 4). Note that the Sun is not at the origin.

Body 1: _ Body 2: ___ Body 3:

B. Predict what will happen when you run the simulation. Explicitly compare bodies 2, 3, and 4 to each other. Explain your reasoning.

C. Run the simulation.

a. Describe what happened to each of the three small bodies.

b. Is this what you expected? Why did it behave this way? 
D. Now, make the following changes to the first case (ellipse preset with initial velocities set to 0), predict what you think will happen to the three small bodies, run the simulation, and record what actually happened, comparing it to the behavior of the initial case, specifically looking at how long it takes the planets to collide with the Sun.

\begin{tabular}{lll}
\hline First case & What happened: & \\
\hline Change & Prediction & What happened? \\
\hline
\end{tabular}

Double the mass of the planets

Double the mass of the Sun (reset the

mass of the planets)

Halve the original mass of the Sun

Considering each of the changes made in the above table, come up with one unifying explanation that explains how the changes made to the masses of the bodies affected the motion of the planets.

E. Two students are asked about how doubling the mass of the planet affects the gravitational force between the Sun and the planet.

Student 1: When I doubled the mass of the planets, the motion remained the same. So, the gravitational force does not depend on the mass of the planet.

Student 2: But the gravitational force comes from the interaction of the two bodies; so it depends on both of the mass of the Sun and the mass of the planet.

Student 1: If the force is twice as big, how come the smaller bodies didn't fall any faster? With which student do you agree? Explain your reasoning.

F. Let's tie this whole section together. Why does changing the Sun's mass affect the motion, but changing the planet's mass doesn't?

\section{APPENDIX C: TRANSCRIPTION KEY}

Conversation Analytic Transcription Conventions

\begin{tabular}{|c|c|}
\hline . & (period) falling intonation. \\
\hline$?$ & (question mark) rising intonation. \\
\hline , & (comma) continuing intonation. \\
\hline- & (hyphen) abrupt cut-off. \\
\hline$::$ & (colon(s)) elongation of sound. \\
\hline word & (underlining) stress. \\
\hline word & The more underlining, the greater the stress. \\
\hline$\overline{\text { WORD }}$ & (all caps) loud speech. \\
\hline${ }^{\circ}$ word $^{\circ}$ & (degree symbols) quiet speech. \\
\hline$\uparrow$ word & (upward arrow) raised pitch. \\
\hline$\downarrow$ word & (downward arrow) lowered pitch. \\
\hline$>$ word $<$ & (more than and less than) quicker speech. \\
\hline$<$ word $>$ & (less than \& more than) slowed speech. \\
\hline$<$ & (less than) jump start or rushed start. \\
\hline hh & (series of h's) aspiration or laughter. \\
\hline.$h h$ & (h's preceded by dot) inhalation. \\
\hline (hh) & (h's in parentheses) inside word boundaries. \\
\hline [] & (brackets) simultaneous or overlapping speech. \\
\hline$=$ & (equal sign) latch or contiguous utterances of the same speaker. \\
\hline$(2.4)$ & (number in parentheses) length of a silence in 10ths of a second. \\
\hline (.) & (period in parentheses) micro-pause, 0.2 second or less. \\
\hline 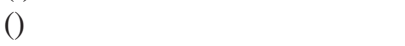 & (empty parentheses) non-transcribable segment of talk. \\
\hline$(($ gazing toward the ceiling $))$ & (double parentheses, italics) nonverbal activity. \\
\hline & (brackets) simultaneous verbal and nonverbal conduct \\
\hline (try 1$) /(\operatorname{try} 2)$ & (two parentheses separated by a slash) alternative hearings. \\
\hline \$word\$ & (dollar or pound signs) smiley voice. \\
\hline \#word\# & (number signs) squeaky voice. \\
\hline LL & double Ls- more than one learner \\
\hline
\end{tabular}

[from H.Z. Waring, Theorizing Pedagogical Interaction: Insights from Conversation Analysis (Routledge, New York, 2015)]. 
[1] A. Elby, Helping physics students learn how to learn, Am. J. Phys. 69, S54 (2001).

[2] E. F. Redish and D. Hammer, Reinventing college physics for biologists: Explicating an epistemological curriculum, Am. J. Phys. 77, 629 (2009).

[3] D. Hu and N.S. Rebello, Shifting college students' epistemological framing using hypothetical debate problems, Phys. Rev. ST Phys. Educ. Res. 10, 010117 (2014).

[4] B.S. Ambrose, P. R. L. Heron, S. Vokos, and L. C. McDermott, Student understanding of light as an electromagnetic wave: Relating the formalism to physical phenomena, Am. J. Phys. 67, 891 (1999).

[5] S. L. Chang and P. S. Shaffer, Curriculum development to improve student understanding of rolling motion, in presented at the Physics Education Research Conference 2018, Washington, DC (2018), https://www.compadre.org/ Repository/document/ServeFile.cfm?ID=14972\&DocID= 5031.

[6] C. C. Chase, J. T. Shemwell, and D. L. Schwartz, Explaining across contrasting cases for deep understanding in science: An example using interactive simulations, in Proceedings of the 9th International Conference of the Learning Sciences-Vol. 1 (International Society of the Learning Sciences, Chicago, Illinois, 2010), pp. 153-160.

[7] H. G. Close, L. S. Gomez, and P. R. L. Heron, Student understanding of the application of Newton's second law to rotating rigid bodies, Am. J. Phys. 81, 458 (2013).

[8] M. J. Cochran and P. R. L. Heron, Development and assessment of research-based tutorials on heat engines and the second law of thermodynamics, Am. J. Phys. 74, 734 (2006).

[9] P. R. L. Heron, M. E. Loverude, P. S. Shaffer, and L. C. McDermott, Helping students develop an understanding of Archimedes' principle. II. Development of research-based instructional materials, Am. J. Phys. 71, 1188 (2003).

[10] Z. Isvan and C. Singh, Improving student understanding of Coulomb's Law and Gauss's Law, AIP Conf. Proc. 883, 181 (2007).

[11] C. H. Kautz, P. R. L. Heron, M. E. Loverude, and L. C. McDermott, Student understanding of the ideal gas law, Part I: A macroscopic perspective, Am. J. Phys. 73, 1055 (2005).

[12] E. Kuo and C. E. Wieman, Seeking instructional specificity: An example from analogical instruction, Phys. Rev. ST Phys. Educ. Res. 11, 020133 (2015).

[13] B. A. Lindsey, P. R. L. Heron, and P. S. Shaffer, Student ability to apply the concepts of work and energy to extended systems, Am. J. Phys. 77, 999 (2009).

[14] J. T. Shemwell, C. C. Chase, and D. L. Schwartz, Seeking the general explanation: A test of inductive activities for learning and transfer, J. Res. Sci. Teach. 52, 58 (2015).

[15] K. Wosilait, P. R. L. Heron, P. S. Shaffer, and L. C. McDermott, Addressing student difficulties in applying a wave model to the interference and diffraction of light, Am. J. Phys. 67, S5 (1999).

[16] L. C. McDermott and P. S. Shaffer, Research as a guide for curriculum development: An example from introductory electricity. Part I: Investigation of student understanding, Am. J. Phys. 60, 994 (1992).
[17] P. S. Shaffer and L. C. McDermott, Research as a guide for curriculum development: An example from introductory electricity. Part II: Design of instructional strategies, Am. J. Phys. 60, 1003 (1992).

[18] L. C. McDermott, P.S. Shaffer, and M. D. Somers, Research as a guide for teaching introductory mechanics: An illustration in the context of the Atwood's machine, Am. J. Phys. 62, 46 (1994).

[19] J. Guisasola, J. L. Zubimendi, and K. Zuza, How much have students learned? Research-based teaching on electrical capacitance, Phys. Rev. ST Phys. Educ. Res. 6, 020102 (2010).

[20] K. Wosilait, P. R. L. Heron, P. S. Shaffer, and L. C. McDermott, Development and assessment of a researchbased tutorial on light and shadow, Am. J. Phys. 66, 906 (1998).

[21] C. Lindstrøm and M. D. Sharma, Teaching physics novices at university: A case for stronger scaffolding, Phys. Rev. ST Phys. Educ. Res. 7, 010109 (2011).

[22] L. Bao and E.F. Redish, Understanding probabilistic interpretations of physical systems: A prerequisite to learning quantum physics, Am. J. Phys. 70, 210 (2002).

[23] S.-Y. Lin and C. Singh, Effect of scaffolding on helping introductory physics students solve quantitative problems involving strong alternative conceptions, Phys. Rev. ST Phys. Educ. Res. 11, 020105 (2015).

[24] C. R. Gette, M. Kryjevskaia, M. R. Stetzer, and P. R. L. Heron, Probing student reasoning approaches through the lens of dual-process theories: A case study in buoyancy, Phys. Rev. Phys. Educ. Res. 14, 010113 (2018).

[25] N. S. Podolefsky and N. D. Finkelstein, Analogical scaffolding and the learning of abstract ideas in physics: An example from electromagnetic waves, Phys. Rev. ST Phys. Educ. Res. 3, 010109 (2007).

[26] P. M. Groves and R. F. Thompson, Habituation: a dualprocess theory, Psychol. Rev. 77, 419 (1970).

[27] R. McDermott and H. Varenne, Adam, Adam, Adam, and Adam: The cultural construction of a learning disability, in Successful Failure (Routledge, London, 2018), pp. 25-44.

[28] B. Barron, Achieving coordination in collaborative problem-solving groups, J. Learn. Sci. 9, 403 (2000).

[29] E. G. Cohen, Restructuring the classroom: Conditions for productive small groups, Rev. Educ. Res. 64, 1 (1994).

[30] M. Docherty, Collaborative learning: The group is greater than the sum of its parts, in Proceedings of the International Conference on Interactive Collaborative Learning (Springer, Cham, Switzerland, 2018), pp. 26-33.

[31] W. F. Pinar, What is Curriculum Theory? (Routledge, London, 2004).

[32] E. Goffman, Frame Analysis: An Essay on the Organization of Experience (Harvard University Press, Cambridge, MA, 1974), Vol. IX.

[33] D. Tannen, Framing in Discourse (Oxford University Press on Demand, New York, 1993).

[34] H.Z. Waring, Theorizing Pedagogical Interaction: Insights from Conversation Analysis (Routledge, London, 2015), Vol. 155.

[35] R. P. McDermott, K. Gospodinoff, and J. Aron, Criteria for an ethnographically adequate description of concerted activities and their contexts, Semiotica 24, 245 (1978). 
[36] Camtasia Software, Techsmith Camtasia. [Online]. Available: http://discover.techsmith.com/camtasia-branddesktop/?gclid=CjwKEAjwq5LHBRCNOYLf9-GyywYSJAAhOw6mXJXmQupVPo_FZD5QEJOn_fKRlr67Zn9_ 5CRwf0VNOhoCND3w_wcB. [Accessed: 05-Apr-2017].

[37] My Solar System, PhET. [Online]. Available: https://phet .colorado.edu/en/simulation/my-solar-system. [Accessed: 07-Mar-2017].

[38] H. B. Carlone, The cultural production of science in reform-based physics: Girls' access, participation, and resistance, J. Res. Sci. Teach. 41, 392 (2004).

[39] A. Radermacher, G. S. Walia, S. Abufardeh, and O. Myronovych, Guidelines for implementing pair programming in introductory CS courses: Experience report, in Proceedings of the International Conference on Frontiers in Education: Computer Science and Computer Engineering (FECS) (The Steering Committee of The World Congress in Computer Science, Computer Engineering and Applied Computing, Las Vegas, NV, 2014), p. 1.
[40] S. Secules, A. Gupta, A. Elby, and C. Turpen, Zooming out from the struggling individual student: An account of the cultural construction of engineering ability in an undergraduate programming class, J. Eng. Educ. 107, 56 (2018).

[41] B. Barron, When smart groups fail, J. Learn. Sci. 12, 307 (2003).

[42] P. Heller and M. Hollabaugh, Teaching problem solving through cooperative grouping. Part 2: Designing problems and structuring groups, Am. J. Phys. 60, 637 (1992).

[43] K. O'Connor, F. A. Peck, and J. Cafarella, Struggling for legitimacy: Trajectories of membership and naturalization in the sorting out of engineering students, Mind, Culture, Activity 22, 168 (2015).

[44] http://accessnetwork.org.

[45] R. E. Scherr and A. Elby, Enabling informed adaptation of reformed instructional materials, AIP Conf. Proc. 883, 46 (2007). 